\title{
Magnetic properties of iron oxide nanoparticles with a DMSA-modified surface
}

\author{
K. Winiarczyk ${ }^{1} \cdot$ W. Gac ${ }^{2} \cdot$ M. Góral-Kowalczyk ${ }^{3} \cdot$ Z. Surowiec ${ }^{1,4}$ (D)
}

Accepted: 8 November 2021 / Published online: 3 December 2021

(c) The Author(s) 2021

\begin{abstract}
The magnetic properties of magnetite nanoparticles $\left(\mathrm{Fe}_{3} \mathrm{O}_{4} \mathrm{NPs}\right)$ strongly depend on their chemical and physical parameters, which can be regulated by a controlled synthesis process. To improve the quality of the obtained nanoparticles, their surface is often modified with organic compounds (from the group of surfactants, sugars, proteins, or organic acid). In this study, we synthesized magnetite nanoparticles with a surface modified with the organic compound DMSA. Then, the nanocrystallites were characterized in terms of structure and morphology. To investigate the role of DMSA and to understand the adsorption mechanism, FTIR measurements were carried out. Using Mössbauer spectroscopy, we investigated temperature-induced changes in the magnetic properties of prepared samples. The spectra were recorded in a wide temperature range (from $4 \mathrm{~K}$ to $390 \mathrm{~K}$ ) for two types of samples: powders and ferrofluids with various concentrations. In the case of powder samples, the superparamagnetic doublet appeared at room temperature. For magnetic suspensions, the spectra were more complicated. They consisted of superposition of asymmetrically broadened sextets and doublets, which was caused by the occurrence of longrange dipole-dipole interactions. These interactions affected the magnetic properties of the material and increased the blocking temperature. Additionally, the magnetic hysteresis and zero field cooling-field cooling (ZFC/FC) curves were measured with the use of a vibrating sample magnetometer.
\end{abstract}

Keywords Magnetic nanoparticles $\cdot$ Superparamagnetism $\cdot$ Mössbauer spectroscopy · Co-precipitation method

This article is part of the Topical Collection on Proceedings of the International Conference on the Applications of the Mössbauer Effect (ICAME 2021), 5-10 September 2021, Brasov, Romania Edited by Victor Kuncser

Z. Surowiec

zbigniew.surowiec@umcs.pl

1 Institute of Physics, Maria Curie-Sklodowska University, Maria Curie-Sklodowska Sq. 1, 20-031 Lublin, Poland

2 Department of Chemical Technology, Faculty of Chemistry, Maria Curie-Sklodowska University, Maria Curie-Sklodowska Sq. 3, 20-031 Lublin, Poland

3 Department of Agricultural Forestry and Transport Machines, Faculty of Production Engineering, University of Life Sciences in Lublin, 28 Głęboka Str, 20-612 Lublin, Poland

4 Frank Laboratory of Neutron Physics, Joint Institute for Nuclear Research, Dubna, Russia 


\section{Introduction}

Due to their chemical and physical properties, iron oxide nanoparticles (mainly magnetite $\mathrm{Fe}_{3} \mathrm{O}_{4}$ and maghemite $\gamma-\mathrm{Fe}_{2} \mathrm{O}_{3}$ ) are widely used in many fields of science. Their low toxicity, interesting magnetic properties, and biocompatibility make them desirable for advanced medical applications such as drug and heat delivery (targeted therapy and magnetic fluid hyperthermia), bioimaging (magnetic resonance imagining contrast), or tissue engineering $[1,2]$. It is worth underlining that $\mathrm{Fe}_{3} \mathrm{O}_{4}$ NPs exhibit superparamagnetism at room temperature, which means that they can be manipulated by an influence of an alternating external magnetic field. Superparamagnetism is a form of magnetism characteristic for ferromagnetic or ferrimagnetic materials with sufficiently small nanoparticles. Reduction of the size of ferromagnetic material to a certain critical volume makes the creation of the domain structure unfavourable (the energy of creating domain walls exceeds the energy gain resulting from the division of the molecule into domains). Then, such a particle is treated as single-domain [3]. Due to the small size, the magnetic energy of anisotropy is smaller or comparable with the thermal energy of crystal lattice vibrations. This results in overcoming the energy barrier, which in turn leads to spontaneous fluctuations of the nanoparticle magnetisation vector. The height of this barrier decreases as the size of nanocrystallites decreases; therefore, smaller crystallites are more susceptible to changing the orientation of magnetic moments $[4,5]$. This unique property allows the conversion of electromagnetic energy to heat. When magnetic nanoparticles (MNPs) are located at the tumour site, the generated heat can be used to destroy cancer cells or pathogenic microbes. The method of treatment that utilizes a colloidal suspension of superparamagnetic nanoparticles is called magnetic fluid hyperthermia (MFH). MFH has many advantages compared to conventional methods of cancer treatment. First of all, heat is generated only in the target place, which increases the efficiency and selectivity of the method. Moreover, healthy tissues are not exposed to heat. The frequencies of the oscillating magnetic field usually used in MFH are harmless to the human organism. Additionally, hyperthermia based on MNPs can also be used for controlled delivery of drugs. It is worth emphasizing that the usefulness and effectiveness of MNPs strongly depend on their physical and chemical parameters, which can be regulated in the synthesis process [6].

In the present investigation, magnetite nanoparticles were synthesized with the coprecipitation method from an alkaline solution and were surface modified with meso-2,3-dimercaptosuccinic acid (DMSA). The magnetic properties of the prepared $\mathrm{Fe}_{3} \mathrm{O}_{4}$ nanoparticles were studied using Mössbauer spectroscopy. Magnetic hysteresis and ZFC/FC curves were measured using a vibrating sample magnetometer. FTIR spectroscopy was performed to achieve precise insight into the surface chemistry of $\mathrm{Fe}_{3} \mathrm{O}_{4}$ NPs coated with DMSA. Additionally, the thermal properties of the synthesized nanopowder were tested using the NanoTherics Magnetherm device.

\section{Experimental}

\subsection{Synthesis of magnetite nanoparticles}

The magnetite nanoparticles were prepared with the co-precipitation method from an alkaline ammonia solution. All reagents were of analytical grade and purchased from 
Sigma-Aldrich. Iron (III) chloride hexahydrate and iron (II) chloride tetrahydrate were the precursors used in the synthesis of $\mathrm{Fe}_{3} \mathrm{O}_{4}$ NPs. Weighed amounts of the iron precursors (the molar ratio of $\mathrm{Fe}^{2+} / \mathrm{Fe}^{3+}$ was 1:2) were dissolved in distilled water and mixed. The mixture of iron ions was added dropwise to the $3.89 \mathrm{M}$ ammonium base solution under vigorous stirring (500 rpm). To ensure an oxygen-free environment, nitrogen was bubbled through the solution. The synthesis was carried out at room temperature. The resulting black precipitate was pulled with a magnet to the bottom of the beaker and washed several times with distilled water to remove the solvent. After that, $300 \mu \mathrm{l}$ of the prepared sample were modified with $7 \mathrm{mM}$ of DMSA. The unmodified sample was used as the reference probe. For more details about the synthesis, see [7, 8].

Additionally, to study the dependence of the interactions between nanoparticles on the concentration, the sample was investigated with the use of Mössbauer Spectroscopy in two forms: powder and ferrofluid (frozen suspension) at two concentrations: $6.0 \mathrm{mg} / 100 \mu \mathrm{l}$ and $2.3 \mathrm{mg} / 100 \mu \mathrm{l}$.

\subsection{Characterization}

The average particle diameter was determined with use of the Williamson-Hall method from X-ray diffraction (XRD) measurement. The XRD pattern was obtained with a Philips $\mathrm{X}$ 'Pert using a diffractometer with $\mathrm{CuK} \alpha$ radiation at room temperature.

Samples with a modified and unmodified surface were investigated with Fourier Transform Infrared Spectroscopy using the attenuated total reflection technique (FTIR-ATR). The spectra were recorded by means of a Nicolet 6700 (Thermo Scientific) spectrometer equipped with Smart Orbit ATR accessory (Thermo Scientific) in the range of 400$4000 \mathrm{~cm}^{-1}$ with the resolution of $4 \mathrm{~cm}^{-1}$, scan velocity 0.6329 , and maximum source aperture. Interferograms of 256 scans were averaged for each spectrum. The spectra were corrected by application of a suitable baseline and Advanced ATR correction function implemented within Omnic software.

Moreover, the sample was examined with Mössbauer Spectroscopy in a wider temperature range in two forms: powder and ferrofluid (frozen suspensions). All Mössbauer spectra were recorded in the transmission mode using a constant acceleration spectrometer. The low-temperature data were obtained with the sample mounted in a $4 \mathrm{~K}$ Closed Cycle Refrigerator System from Janis and SHI (Woburn, MA). A ${ }^{57}$ Co source in a Rh matrix and $\alpha$-Fe standard were used. The Mössbauer spectra were developed by hyperfine magnetic field distributions.

The thermal properties of the synthesized nanopowder were tested using the NanoTherics Magnetherm device. The ZFC/FC curve and the hysteresis curves of the magnetic moment were obtained using a Superconducting Quantum Interference Device (SQUID) magnetometer MPMS3 from Quantum Design.

\section{Results and discussion}

\subsection{XRD results}

The crystal structure of the sample was verified by powder X-ray diffraction (XRD). The $2 \theta$ values were taken from $20^{\circ}$ to $80^{\circ}$ using $\mathrm{Cu} \mathrm{K} \alpha$ radiation. Figure 1 shows the XRD patterns for the nanosized magnetite powder and the reference pattern of bulk magnetite 
Fig. 1 XRD patterns for the sample of nanosized magnetite and the reference pattern of bulk magnetite

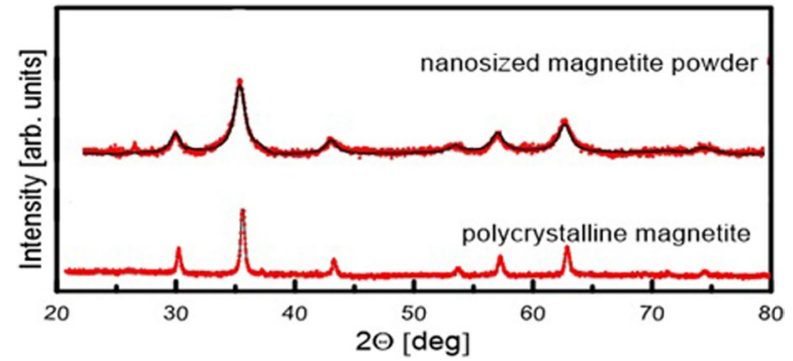

(polycrystalline magnetite). The shapes and arrangement of the main reflections for these two samples are analogous, which indicates the existence of the same phase. The absence of other interference maxima indicates that the sample does not contain crystalline impurities. In addition, the dark black colour and strong magnetic properties of dried powders of magnetic fluids are a characteristic of magnetite amongst other iron oxides. All Bragg's planes were indexed to the face-centred cubic inverse spinel magnetite of the $F d 3 m$ space group. The obtained lattice constant for nanosized magnetite powder $a$ is $8.352 \AA$, whereas the same for bulk magnetite is $8.396 \AA$. This observation may indicate the presence of vacancies in nanoparticles, which lead to unit cell contraction.

Visible differences appear in the width of the diffraction peaks. The strongly broadened peaks in the X-ray diffraction patterns are characteristic for nanoparticles. The mean size of the crystallites was calculated from the Williamson-Hall analysis. The average diameter (D) of the particles in the prepared sample was $8.3 \mathrm{~nm}$.

\subsection{FTIR-ATR results}

The mechanism of DMSA adsorption on the surface of the $\mathrm{Fe}_{3} \mathrm{O}_{4}\left(\mathrm{Fe}_{3} \mathrm{O}_{4} @\right.$ DMSA) nanoparticles was investigated with the Fourier Transform Infrared Spectroscopy using FTIRATR technique. Figure 2 shows the FTIR spectra of pure DMSA $\left(\mathrm{C}_{4} \mathrm{H}_{6} \mathrm{O}_{4} \mathrm{~S}_{2}\right)$, bare magnetite nanoparticles, and $\mathrm{Fe}_{3} \mathrm{O}_{4}$ NPs coated with DMSA.

Well-resolved absorption bands are visible for the DMSA sample. The bands located in the range of $3800-3000 \mathrm{~cm}^{-1}$ correspond to stretching vibrations of $\mathrm{O}-\mathrm{H}$ and inter- and intra-molecular hydrogen-bonded carboxylic acid groups $(\mathrm{OH} \cdots \mathrm{O}-\mathrm{C})$ [9]. The presence of carboxyl groups in the DMSA molecule is manifested on the spectra as a strong band at $1698 \mathrm{~cm}^{-1}$ ascribed to the stretching vibrations of the carbonyl group $(\nu \mathrm{C}=\mathrm{O})$ and weaker bands of $\nu \mathrm{C}-\mathrm{O}$ located between 1200 and $1130 \mathrm{~cm}^{-1}$. The presence of $-\mathrm{OH}$ in-plane deformation can be ascribed to the band at $1422 \mathrm{~cm}^{-1}$. In turn, the C-O asymmetric stretching vibration can be assigned to the bands near 1190 and $1180 \mathrm{~cm}^{-1}$. The band at $928 \mathrm{~cm}^{-1}$ corresponds to the $\mathrm{OH}$ out-of-plane deformation, characteristic for a carboxylic dimer. The vibration bands near 2970 and $2830 \mathrm{~cm}^{-1}$ correspond to the asymmetric and symmetric stretching $\mathrm{C}-\mathrm{H}$ vibrations. The deformation vibrations of $\mathrm{C}-\mathrm{H}$ groups are visible in the range of $1330-1215 \mathrm{~cm}^{-1}$. The strong maxima at 2562 and $2536 \mathrm{~cm}^{-1}$ result from the presence of S-H stretching vibrations. The C-S stretching vibrations are observed at $693 \mathrm{~cm}^{-1}$. The bands located at $425,556,625$, and $700 \mathrm{~cm}^{-1}$ may indicate the presence of $\mathrm{Fe}-\mathrm{O}$ stretching vibrations in the iron oxide particles $[10,11]$.

In the FTIR spectrum of $\mathrm{Fe}_{3} \mathrm{O}_{4}$ NPs, a characteristic peak of magnetite is observed in the range of $550-630 \mathrm{~cm}^{-1}$; in our case, the peak at $576 \mathrm{~cm}^{-1}$ indicates the presence 


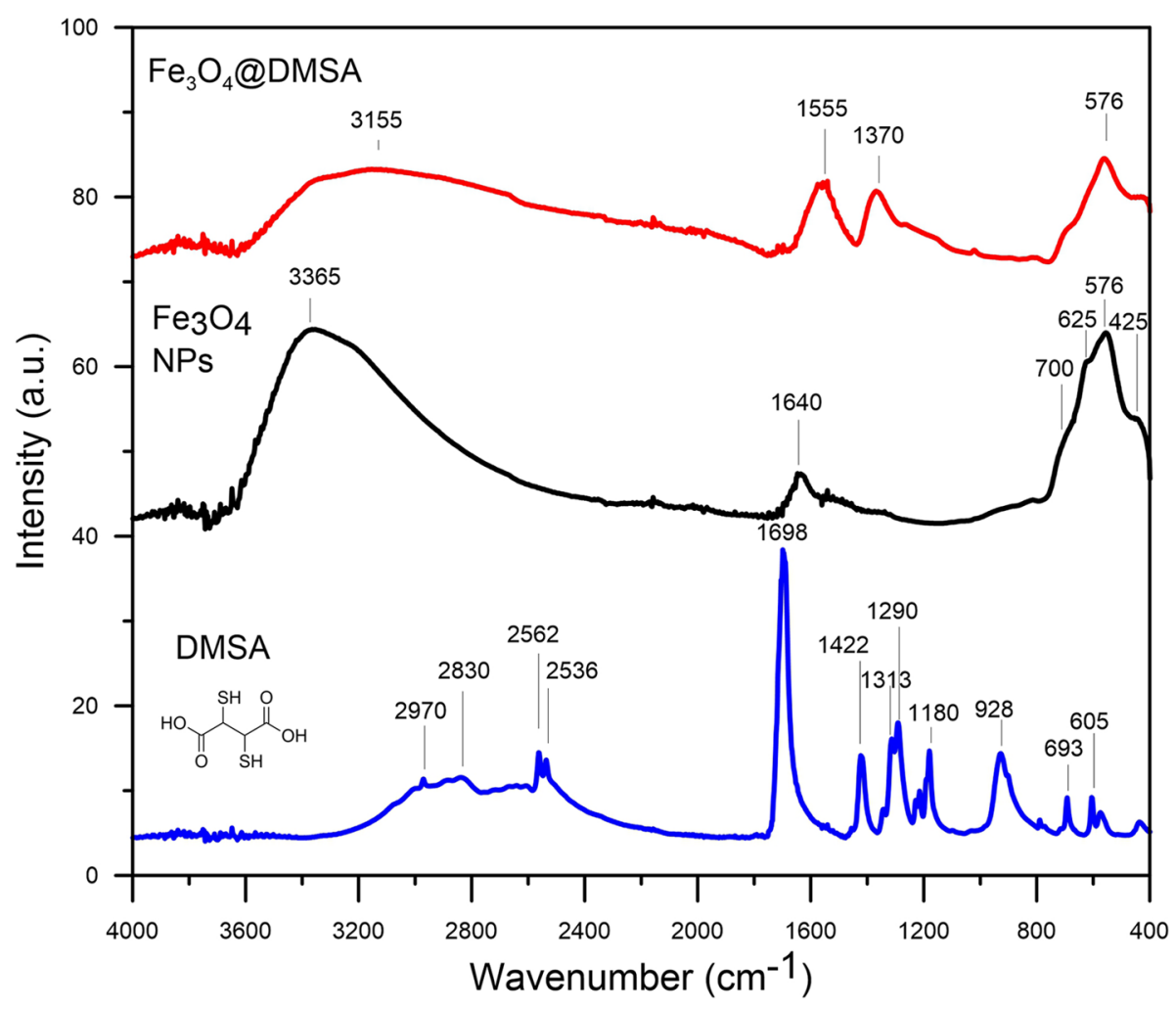

Fig. 2 FT-IR spectra of pure DMSA, bare $\mathrm{Fe}_{3} \mathrm{O}_{4} \mathrm{NPs}$, and DMSA-coated $\mathrm{Fe}_{3} \mathrm{O}_{4}$ NPs

of magnetite with a face-centred reverse spinel structure, which was also indicated by the X-ray analysis. In this range, the absorption band is caused by the vibrations of the $\mathrm{Fe}-\mathrm{O}$ bonds in the tetrahedral and octahedral positions [12]. The wide absorption bands located between 3800 and $2700 \mathrm{~cm}^{-1}$ can be ascribed to the vibrations of hydroxyl groups bounded to the surface of the iron oxide nanoparticles. These groups come from the environment from which the nanoparticles were precipitated (aqueous ammonia solution) [13].

The intensity of the vibration bands is lower in the DMSA-modified samples. The absorption bands of the characteristic groups of DMSA molecules are not clearly visible on the spectra of iron nanoparticles. The irregular bands located between 1200 and $1500 \mathrm{~cm}^{-1}$ on the spectra can be ascribed to the symmetric and asymmetric stretching vibration bands of the carboxylate group $\left(\mathrm{COO}^{-}\right)$. The differences in the band intensity and position in this range of the spectra of bare magnetite and DMSA-coated $\mathrm{Fe}_{3} \mathrm{O}_{4}$ samples may indicate different concentrations and surface arrangement of carboxyl groups (including the chelating bidentate and unidendate configuration and hydrogen bonding interactions). In the resulting chelate, the hydrogen atoms have been replaced with heavier iron atoms. The absorption band at $1640 \mathrm{~cm}^{-1}$ can be related to the bending vibrations of surface hydroxyl groups and may indicate molecular adsorption without ionisation $[14,15]$. 

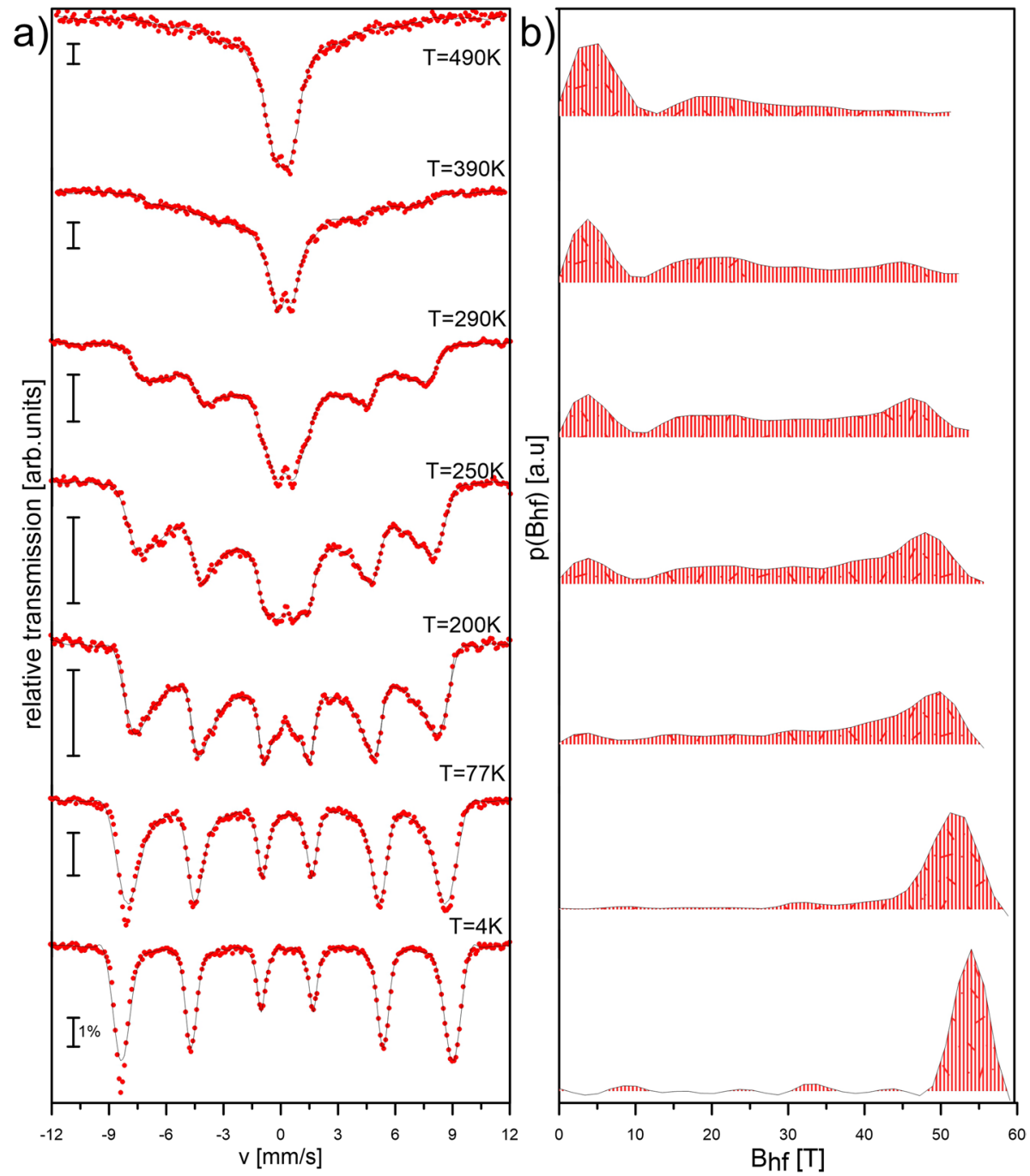

Fig. 3 a) Mössbauer spectra and b) hyperfine magnetic field distributions for the powder sample $(\mathrm{D}=8.3 \mathrm{~nm})$ recorded at temperatures in the range from $4 \mathrm{~K}$ to $490 \mathrm{~K}$. The marker placed below the spectrum indicates $1 \%$ relative transmission

\subsection{Mössbauer spectra}

Figure 3 shows the Mössbauer spectra of the sample in the powder form measured at different temperatures. At a low temperature, a symmetrical sextet is observed. An additional component, i.e. the superparamagnetic doublet, appears at $77 \mathrm{~K}$. As the temperature rises, a gradual transformation of the sextet into a doublet appearing in the middle part of the spectral area can be noticed. At RT, the majority of the sample is in the superparamagnetic state, whereas all nanoparticles fluctuate at $390 \mathrm{~K}$ (the interparticle interactions are neglected). A decrease in the average value of the internal magnetic field is also observed. 

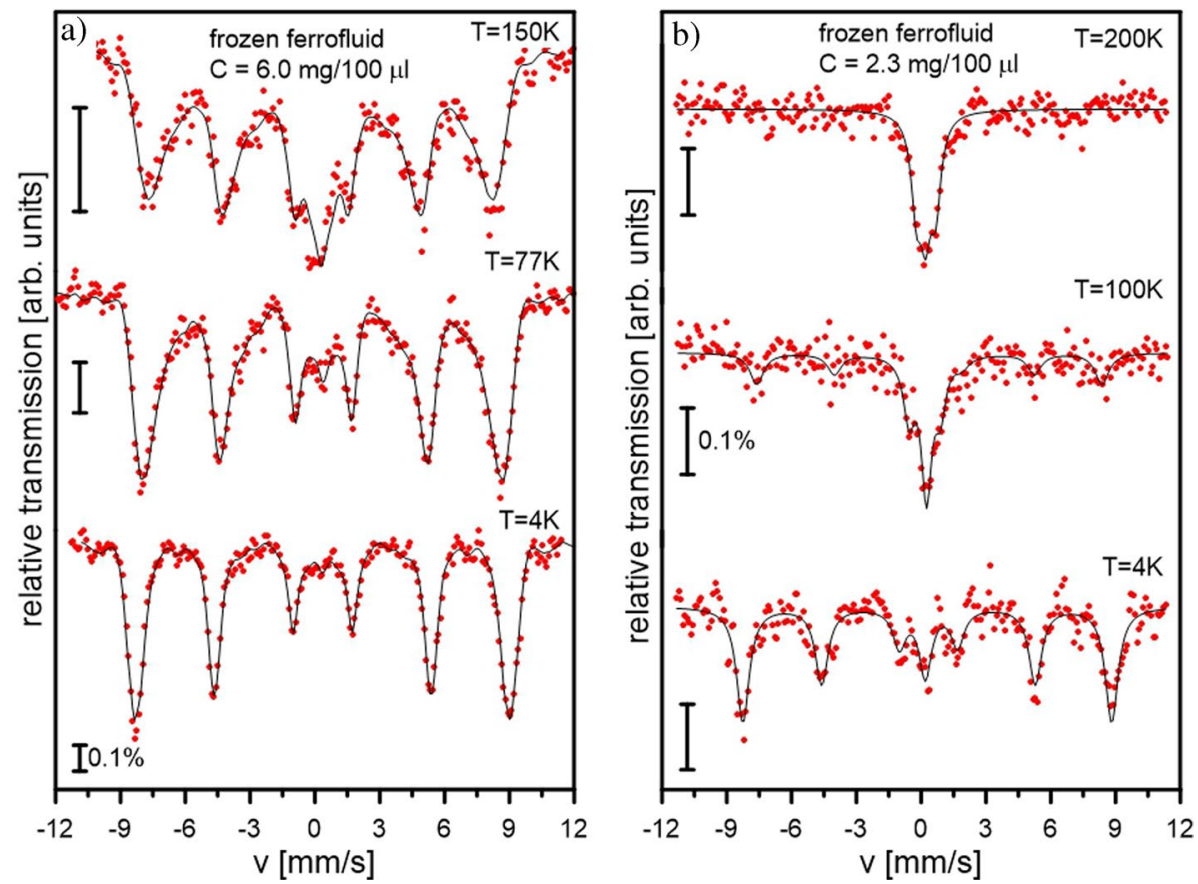

Fig. 4 Mössbauer spectra for the sample in the form of frozen suspensions at concentrations of $6.0 \mathrm{mg} / 100 \mu \mathrm{l}(a)$ and $2.3 \mathrm{mg} / 100 \mu \mathrm{l}(b)$. The marker placed below the spectrum indicates $0.1 \%$ relative transmission for each sample

Additionally, spectra of the sample were evaluated by hyperfine magnetic field distributions. Along with the temperature evolution, the magnetic field significantly decreases. The broadened hyperfine magnetic field distributions indicate the existence of interparticle interactions. At room temperature, the magnetic field is evenly distributed, which indicates the interaction between particles and the existence of both paramagnetic and ferromagnetic phases [16-18].

Figure 4 presents Mössbauer spectra of the sample in the form of frozen suspensions at concentrations of $6.0 \mathrm{mg} / 100 \mu \mathrm{l}$ and $2.3 \mathrm{mg} / 100 \mu \mathrm{l}$. These spectra are more complicated. In the case of the more concentrated ferrofluid suspension, the spectrum recorded at $4 \mathrm{~K}$ is similar to the spectrum for the powder sample. With the increasing temperature, the lines become wider and asymmetrical. The explanation is that the relaxation is influenced by magnetic interactions between nanoparticles (long-range dipole-dipole interactions). Strong magnetic dipole interactions are difficult to avoid due to the broad particle size distribution. At $200 \mathrm{~K}$, only a small fraction of the nanoparticles is in the superparamagnetic state. Interparticle interactions strongly affect the blocking temperature causing its increase. The blocking temperature is defined as a temperature at which half of the spectrum is occupied by a sextet and the other half is occupied by a singlet or a doublet [18, 19]. In the case of a diluted sample, the inter-particle interactions are not as strong as for a concentrated sample. The spectrum shows gradual transition with the temperature increasing from an asymmetrical sextet to a broad singlet, which occupies the whole spectral area at $200 \mathrm{~K}$. 


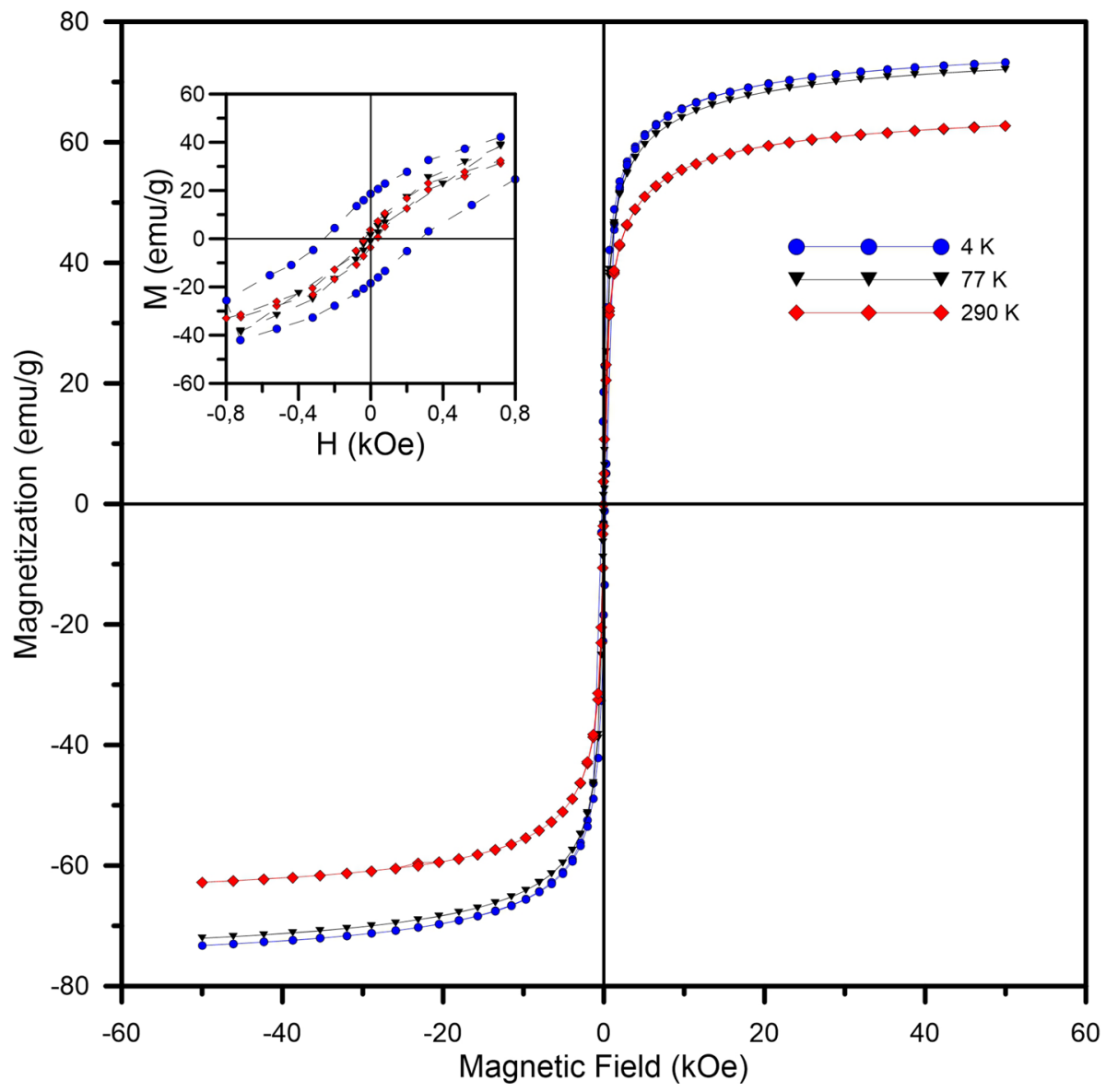

Fig. 5 Magnetisation loops measured for the sample with $\mathrm{D}=8.3 \mathrm{~nm}$ at $4 \mathrm{~K}, 77 \mathrm{~K}$, and $290 \mathrm{~K}$. The inset shows the low field region of the hysteresis loop

\subsection{Magnetic measurements}

In order to characterize the magnetic behaviour of the $\mathrm{Fe}_{3} \mathrm{O}_{4}$ nanocrystals, the hysteresis loop and zero field cooling-field cooling (ZFC/FC) curves were measured with a vibrating sample magnetometer. Figure 5 presents the magnetisation curves for the powder sample at the temperatures of $4 \mathrm{~K}$ (circles), $77 \mathrm{~K}$ (triangles), and $290 \mathrm{~K}$ (squares).

The hysteresis loops apparently pass through the origin, which indicates zero coercivity and zero remanence (Fig. 5), indicating that the samples are in the superparamagnetic state with unstable magnetisation.

The samples exhibit superparamagnetic behaviour without coercivity and remanent magnetisation. The saturation magnetisation value $\left(M_{s}\right)$ is above $70 \mathrm{emu} / \mathrm{g}$ at the temperatures of $4 \mathrm{~K}$ and $77 \mathrm{~K}$ and about $63 \mathrm{emu} / \mathrm{g}$ at room temperature. Upon careful examination of the high-resolution magnetisation data (inset Fig. 5), low coercivity values are observed at $4 \mathrm{~K}$. The appearance of the zero coercivity may be attributed to the long-range magnetic dipolar interactions. 
Fig. 6 ZFC (solid symbol) and FC (open symbol) magnetisation measured under 50 Oe in the heating cycles

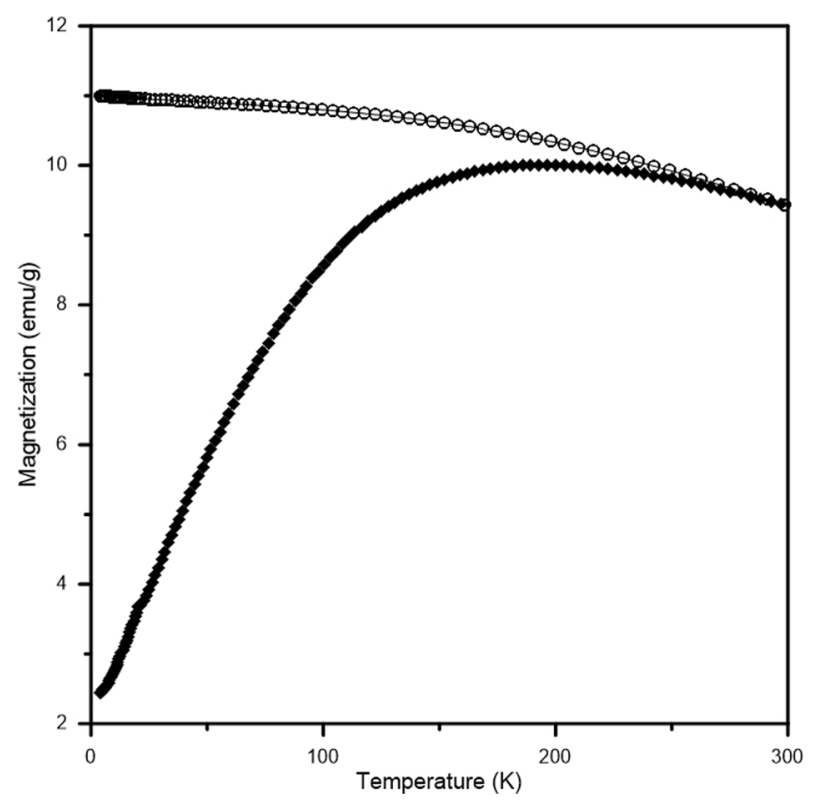

These results are consistent with those obtained for monodisperse magnetic iron oxide nanoparticles via surface double-exchange with DMSA [20, 21].

Figure 6 shows the ZFC-FC curves for the sample with $\mathrm{D}=8.3 \mathrm{~nm}$. The measurements were carried out as follows: demagnetized samples were cooled down from room temperature to $6 \mathrm{~K}$ in the zero magnetic field; then, a 50 Oe magnetic field was applied and the magnetisation was measured during heating the sample to $300 \mathrm{~K}$, determining the ZFC curve. Next, maintaining the value of the magnetic field, the samples were cooled again to $6 \mathrm{~K}$ and the magnetisation was measured as a function of temperature (FC curve). It can be noticed that, in the case of the ZFC mode, the magnetisation increased rapidly. Moreover, the ZFC and FC curves showed irreversibility, which is characteristic of the process of nanoparticle assembly blocking [22, 23].

\subsection{Calorimetric measurements}

Finally, we investigated experimentally the influence of an alternating electromagnetic field on the heat generation rate expressed in terms of the Specific Absorption Rate (SAR) and Specific Loss Power (SLP).

SAR is commonly defined as the heating power $(P$, measured in $\mathrm{W})$ generated per unit mass $\left(m_{\mathrm{MNP}}\right.$, measured in $\left.\mathrm{g}\right)$ :

$$
S A R=\frac{P}{m_{M N P}}
$$

The power generated by MNPs depends on the physical and magnetic properties of these MNPs. However, the dissipated power depends linearly on the frequency $(f$, measured in $\mathrm{Hz})$ and squarely on the magnetic field strength $\left(H\right.$, measured in $\left.\mathrm{A} \cdot \mathrm{m}^{-1}\right)$. 


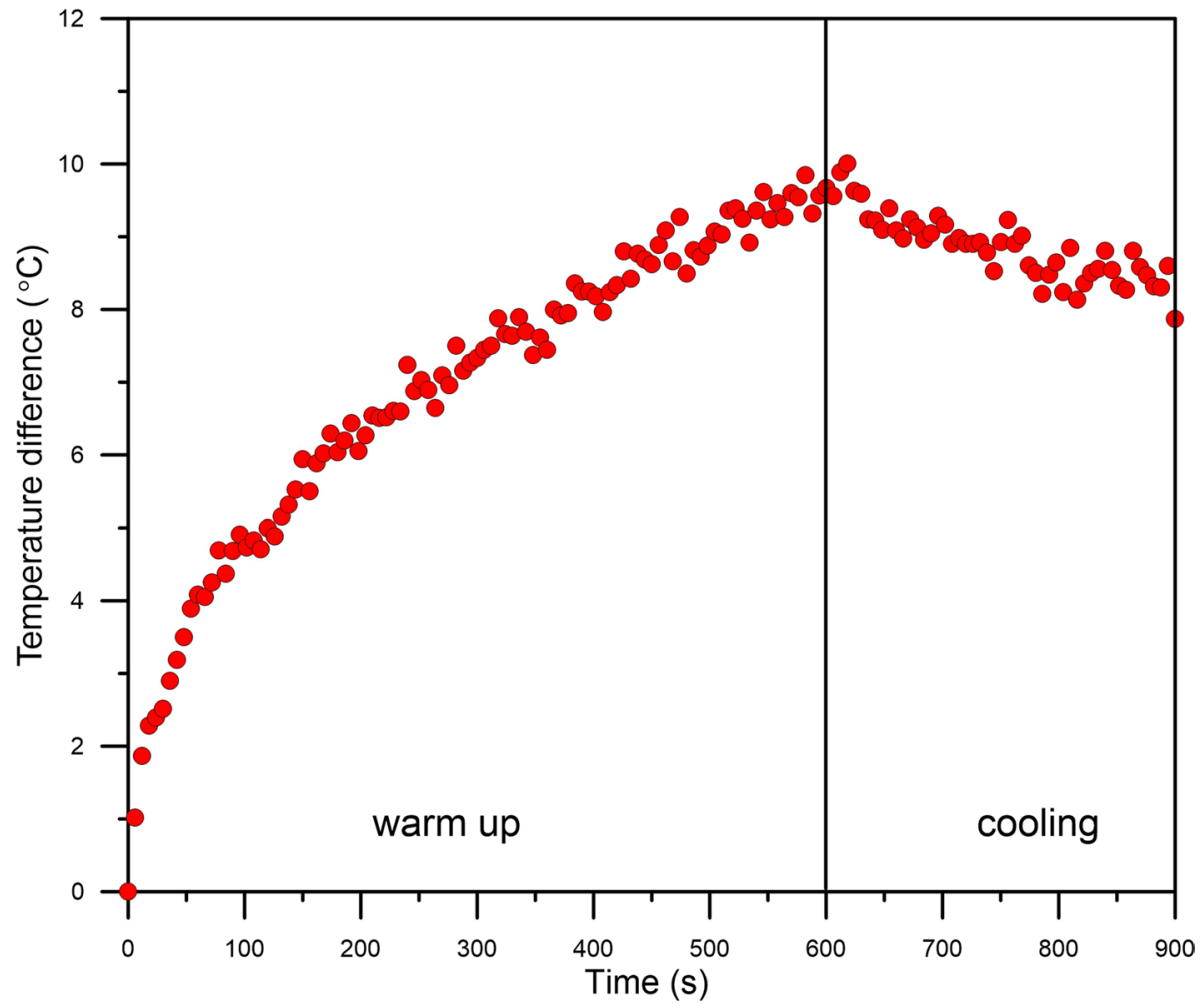

Fig. 7 Time-dependent temperature increase. Values of SAR determinable by the initial temperature transient

In order to become independent from these external factors, it has become common to use the concept of internal loss power (ILP, measured in $\mathrm{Hm}^{2} \mathrm{~g}^{-1}$ ) [24]

$$
I L P=\frac{S A R}{f H^{2}},
$$

which, in the rather more convenient units of nanoHenrys $\mathrm{m}^{2}$ per $\mathrm{kg}$ used in clinical practice, is computed as:

$$
I L P\left[n \mathrm{Hm}^{2} \mathrm{~kg}^{-1}\right]=\frac{S A R\left[\mathrm{Wkg}^{-1}\right]}{f[\mathrm{kHz}] H^{2}\left[\mathrm{kAm}^{-1}\right]^{2}},
$$

The measurement was carried out in the following way. The sample in the form of ferrofluid $(5 \mathrm{mg} / \mathrm{ml})$ was placed in a $1.5 \mathrm{ml}$ Eppendorf tube and then in a polystyrene jacket for thermal protection. Next, the sample was exposed to the alternating magnetic field $(f=532 \mathrm{kHz}, H=10 \mathrm{kA} / \mathrm{m})$. The ferrofluid was heated under the influence of an external alternating magnetic field. After $600 \mathrm{~s}$, the field was disabled. The results of our experiments are shown in Fig. 7.

Different models can be used to determine quantitative parameters describing the thermal properties of the sample: SAR and ILP. The Initial Slope method (ISM) and its 
extension, i.e. the Corrected Slope Method (CSM), are most common [25]. In ISM assuming that thermal losses are negligible at the start of the heating process, SAR is calculated as:

$$
S A R_{I S M}=\left.\frac{C}{m_{M N P}} \frac{\Delta T}{\Delta t}\right|_{t \rightarrow 0},
$$

where $\mathrm{C}$ is the heat capacity of the sample.

CSM corrects the estimates of ISM by considering the early linear losses that occur from the start of the heating process.

$$
S A R_{C S M}=\left(C \frac{d T}{d t}+L \Delta T\right) / m_{M N P}
$$

where $L$ is a linear loss parameter that may be deduced from a Fig. 7 style cooling curve and $\Delta T$ is the (mean) temperature difference between the sample and the baseline, which must be within the bounds of the linear-loss regime.

In present work, the corrected slope method was used. Multiple linear fittings are applied over an interval within the linear loss region. The SAR values are derived from the following equations:

$$
S A R_{C S M}=\frac{1}{N} \sum_{i}^{N} \frac{C\left(\frac{d T}{d t}\right)_{i}+L(\Delta T)_{i}}{m_{M N P}} .
$$

The computations parameters used to calculate SAR and ILP values include the fitting interval $(50 \mathrm{~s})$ and the number of fits $N=8)$. The values of the above parameters obtained for the tested sample are as follows: $\mathrm{SAR}=(7.547 \pm 1.18) \mathrm{W} / \mathrm{g}$ and $\mathrm{ILP}=(0.142 \pm 0.087)$ $\mathrm{nHm}^{2} / \mathrm{kg}$.

The measurement was carried out in non-adiabatic conditions; hence, many factors may influence its result. These include magnetic field heterogeneity, losses related to the conversion of the electric signal into a magnetic field, time effects (time constant related to induction heating, response time of the measuring probe, etc.), heat capacity value, and sample holder (geometry and material from which it is made) [24-27].

\section{Conclusions}

In this paper, $\mathrm{Fe}_{3} \mathrm{O}_{4}$ nanoparticles obtained with the coprecipitation method were investigated in terms of their chemical and physical properties. The coprecipitation method has many advantages, e.g. repeatability, fast, low cost, and high purity of the product. Moreover, by selecting appropriate reaction conditions (amounts of substrates, concentration of the ammonium base, etc.), nanoparticles with the desired size can be generated. The structural research showed that nanoparticles with a diameter of $8.3 \mathrm{~nm}$ were obtained. As shown by the Mössbauer spectra for the powder sample, such nanoparticles exhibit superparamagnetic behaviour even at room temperature. In the case of frozen fluids, for a more concentrated solution, relaxation is influenced by interparticle interactions (asymmetrical and broadened lines are observed). In the diluted sample, the asymmetrical sextet gradually turns into a broadened singlet with increasing temperature. The analysis of IR spectra indicates that, during the modification of the $\mathrm{Fe}_{3} \mathrm{O}_{4} \mathrm{NPs}$, hydrogen atoms from the $\mathrm{COOH}$ 
group were replaced with iron atoms. This caused the disappearance of the absorption band of the $\mathrm{COOH}$ group and the appearance of the asymmetrical and symmetrical absorption bands -OCO-. The DMSA coating increases the stability and biocompatibility of nanomaterials. As indicated by the magnetic measurements, the sample with an average diameter of $8.3 \mathrm{~nm}$ exhibits superparamagnetic behaviour at $290 \mathrm{~K}$ with negligible coercivity and remanent magnetisation. The parameters describing the thermal properties of the sample are as follows: $\mathrm{SAR}=(7.54 \pm 1.18) \mathrm{W} / \mathrm{g}$ and $\mathrm{ILP}=(0.142 \pm 0.087) \mathrm{nHm} / \mathrm{kg}$.

Open Access This article is licensed under a Creative Commons Attribution 4.0 International License, which permits use, sharing, adaptation, distribution and reproduction in any medium or format, as long as you give appropriate credit to the original author(s) and the source, provide a link to the Creative Commons licence, and indicate if changes were made. The images or other third party material in this article are included in the article's Creative Commons licence, unless indicated otherwise in a credit line to the material. If material is not included in the article's Creative Commons licence and your intended use is not permitted by statutory regulation or exceeds the permitted use, you will need to obtain permission directly from the copyright holder. To view a copy of this licence, visit http://creativecommons.org/licenses/by/4.0/.

\section{References}

1. Ansari, S.A.M.K., Ficiarà, E., Ruffinatti, F.A., Stura, I., Argenziano, M., Abollino, O., Cavalli, R., Guiot, C., D’Agata, F.: Magnetic Iron oxide nanoparticles: synthesis, Characterization and Functionalization for Biomedical Applications in the Central Nervous System. Materials. 12, 465-489 (2019). https://doi.org/10.3390/ma12030465

2. Chudzik, B., Miaskowski, A., Surowiec, Z., Czernel, G., Duluk, T., Marczuk, A., Gagoś, M.: Effectiveness of magnetic fluid hyperthermia against Candida albicans cells. Int. J. Hyperth. 32, 842-857 (2016). https://doi.org/10.1080/02656736.2016.1212277

3. Masud, M.K., Na, J., Younus, M.: Superparamagnetic nanoarchitectures for disease-specific biomarker detection. Chem. Soc. Rev. 48, 5717-5751 (2019). https://doi.org/10.1039/c9cs00174c

4. Tong, S., Quinto, C.A., Zhang, L., Tong, P., et al.: Size-dependent heating of magnetic iron oxide nanoparticles. ACS Nano. 11, 6808-6816 (2017). https://doi.org/10.1021/acsnano.7b01762

5. Deatsch, A.E., Evans, B.A.: Heating efficiency in magnetic nanoparticle hyperthermia. J. Magn. Magn. Mater. 354, 163-172 (2014). https://doi.org/10.1016/j.jmmm.2013.11.006

6. Das, P., Colombo, M., Prosperi, D.: Recent advances in magnetic fluid hyperthermia for cancer therapy. Colloid Surface B. 174, 42-55 (2019). https://doi.org/10.1016/j.colsurfb.2018.10.051

7. Surowiec, Z., Budzyński, M., Durak, K., Czernel, G.: Synthesis and characterization of iron oxide magnetic nanoparticles. Nukleonika. 62(2), 73-77 (2017). https://doi.org/10.1515/nuka-2017-0009

8. Durak, K., Wiertel, M., Surowiec, Z., Miaskowski, A.: Positron annihilation in magnetite nanopowders prepared by co-precipitation method. Acta Phys. Pol. A. 132, 1593-1597 (2017). https://doi.org/10. 12693/APhysPolA.132.1593

9. Shaaban, I.A., Karoyo, A., Wilson, L.D., Mohamed, T.A.: Raman and DRIFT spectra, vibrational assignments and quantum mechanical calculations of centrosymmetric meso-2,3-Dimercaptosuccinic acid. Spectrochim. Acta A. 183, 275-283 (2017)

10. Chen, Z.P., Zhang, Y., Zhang, S., Xia, J.G., Liu, J.W., Xu, K., Gu, N.: Preparation and characterization of water-soluble monodisperse magnetic iron oxide nanoparticles via surface double-exchange with DMSA. Colloid Surface A. 316, 210-216 (2008)

11. Wierzbinski, K.R., Szymanski, T., Rozwadowska, N., Rybka, J.D., Zimna, A., Zalewski, T., NowickaBauer, K., Malcher, A., Nowaczyk, M., Krupinski, M., Fiedorowicz, M., Bogorodzki, P., Grieb, P., Giersig, M., Kurpisz, M.K.: Potential use of superparamagnetic iron oxide nanoparticles for in vitro and in vivo bioimaging of human myoblasts. Sci. Rep. UK. 8, 3682-3699 (2018). https://doi.org/10. 1038/s41598-018-22018-0

12. Iyengar, S., Joy, M., Ghosh, C.K., Dey, S., Kotnalad, R.K., Ghosh Magnetic, S.: X-ray and M“ossbauer studies on magnetite/maghemite core-shell nanostructures fabricated through an aqueous route. RSC Adv. 4, 64919 (2014) 
13. Ebrahiminezhad, A., Ghasemi, Y., Rasoul-Amini, S., Bararand, J., Davaran, S.: Bull. Kor. Chem. Soc. 33, 3957 (2012)

14. Buckland, A.D., Rochester, C.H., Topham, S.A.: Infrared study of the adsorption of carboxylic acids on hematite and goethite immersed in carbon tetrachloride. J.C.S. Faraday. I(76), 302-313 (1980)

15. Max, J.J., Chapados, C.: Infrared spectroscopy of aqueous carboxylic acids: comparison between different acids and their salts. J. Phys. Chem. A. 108, 3324-3337 (2004)

16. Dézsi, I., Fetzer, C.S., Gombkötő, Á., Szűcs, I., Gubicza, J., Ungár, T.: Phase transition in nanomagnetite. J. Appl. Phys. 103, 104312-1-104312-5 (2008). https://doi.org/10.1063/1.2937252

17. Polikarpov, M., Cherepanov, V., Chuev, M., Gabbasov, R., Mischenko, I., Jain, N., Jones, S., Hawkett, B., Panchenko, V.: Mössbauer evaluation of the interparticle magnetic interactions within the magnetic hyperthermia beads. J. Magn. Magn. Mater. 380, 347-352 (2015). https://doi.org/10.1016/j.jmmm. 2014.10.025

18. Fock, J., Hansen, M.F., Frandsen, C., Mørup, S.: On the interpretation of Mössbauer spectra of magnetic nanoparticles. J. Magn. Magn. Mater. 445, 11-21 (2018). https://doi.org/10.1016/j.jmmm.2017. 08.070

19. Mørup, S., Hansen, M.F., Frandsen, C.: Magnetic interactions between nanoparticles. Belistein J. Nanotechnol. 1, 182-190 (2010). https://doi.org/10.3762/bjnano.1.22

20. Chen, Z.P., Zhang, Y., Zhang, S., Xia, J.G., Liu, J.W., Xu, K., Gu, N.: Preparation and characterization of water-soluble monodisperse magnetic iron oxide nanoparticles via surface double-exchange with DMSA. Colloid Surface A. 316, 210-216 (2008). https://doi.org/10.1016/j.colsurfa.2007.09.017

21. Mahdavi, M., Ahmad, M.B., Haron, M.J., Namvar, F., Nadi, B., Rahman, M.Z.A., Amin, J.: Synthesis, surface modification and characterisation of biocompatible Magnetic Iron oxide nanoparticles for biomedical applications. Molecules. 18, 7533-7548 (2013). https://doi.org/10.3390/molecules18077533

22. Salas, G., Casado, C., Teran, F.J., Miranda, R., Serna, C.J., Morales, M.P.: Controlled synthesis of uniform magnetite nanocrystals with high-quality properties for biomedical applications. J. Mater. Chem. 22, 21065-21075 (2012). https://doi.org/10.1039/c2jm34402e

23. Cullity Jr., B.D., Graham, C.D.: Introduction to Magnetic Materials, 2nd edn. Wiley-IEEE Press (2008)

24. Ortega, D., Pankhurst, Q.A.: Magnetic hyperthermia. Nanosc. 1, 60-88 (2013). https://doi.org/10. 1039/9781849734844-00060

25. Wildeboer, R.R., Southern, P., Pankhurst, Q.A.: On the reliable measurement of specific absorption rates and intrinsic loss parameters in magnetic hyperthermia materials. J. Phys. D. Appl. Phys. 47, 495003 (2014)

26. Sharma, S.K., Shrivastava, N., Rossi, F., Tung, L.D., Thanh, N.T.K.: Nanoparticles-based magnetic and photo induced hyperthermia for cancer treatment. Nano Today. 29, 100795 (2019). https://doi.org/ 10.1016/j.nantod.2019.100795

27. Raouf, I., Khalid, S., Khan, A., et al.: A review on numerical modelling for magnetic nanoparticle hyperthermia: Progress and challenges. Jour. of Therm. Biol. 91, 102644 (2020). https://doi.org/10. 1016/j.jtherbio.2020.102644

Publisher's note Springer Nature remains neutral with regard to jurisdictional claims in published maps and institutional affiliations. 